\title{
Role of nitric oxide in the periaqueductal gray in defensive behavior in mice: influence of prior local N-methyl-D-aspartate receptor activation and aversive condition
}

\author{
Ricardo Luiz Nunes-de-Souza ${ }^{1,2,3}$,Tarciso Tadeu Miguel ${ }^{1,3}$, Karina Santos Gomes ${ }^{2,3}$, Juliana Sayuri Fugimoto ${ }^{3}$, \\ Joyce Mendes-Gomes ${ }^{2,3}$, Vanessa Cristiane Santana Amaral ${ }^{1,3}$, and Eduardo Ferreira de Carvalho-Netto ${ }^{4}$ \\ 1 Universidade Federal de São Carlos-Universidade Estadual Paulista, Brasil \\ 2 Universidade de São Paulo, Brasil \\ 3 Universidade Estadual Paulista, Brasil \\ 4 University of Cincinnati, USA
}

\begin{abstract}
Glutamate $N$-methyl-D-aspartate (NMDA) receptor activation within the dorsal column of the periaqueductal gray (dPAG) leads to antinociceptive, autonomic, and behavioral responses characterized as the fear reaction. Activation of NMDA receptors in the brain increases nitric oxide (NO) synthesis, and NO has been proposed to be a mediator of the aversive action of glutamate. This paper reviews a series of studies investigating the effects of neuronal NO synthase (nNOS) inhibition in the dPAG of mice in different aversive conditions. nNOS inhibition by infusion of N $\omega$-propyl-L-arginine (NPLA) prevents fear-like reactions (e.g., jumping, running, freezing) induced by NMDA receptor stimulation within the dPAG and produces anti-aversive effects when injected into the same midbrain site in mice confronted with a predator. Interestingly, nNOS inhibition within the dPAG does not change anxiety-like behavior in mice exposed to the elevated plus maze (EPM), but it reverses the effect of an anxiogenic dose of NMDA injected into the same site in animals subjected to the EPM. Altogether, the results support a role for glutamate NMDA receptors and NO in the dPAG in the regulation of defensive behaviors in mice. However, dPAG nitrergic modulation of anxiety-like behavior appears to depend on the magnitude of the aversive stimulus. Keywords: periaqueductal gray matter (PAG), NMDA receptors, neuronal nitric oxide synthase (nNOS), elevated plus maze (EPM), rat exposure test (RET), mouse.
\end{abstract}

Received 20 April 2010; received in revised form 31 May 2010; accepted 31 May 2010. Available on line 26 June 2010

\section{Introduction}

The dorsal portion of the periaqueductal gray (dPAG) has been identified as the principal substrate of aversive states in the midbrain (Graeff, 2004). Electrical or chemical stimulation of the dPAG elicits autonomic (e.g., tachycardia, defecation) and behavioral (e.g., jumping, running, immobility) responses characterized as the fear reaction. Additionally, many lines of evidence have indicated that in addition to fundamentally controlling fear-

Ricardo Luiz Nunes-de-Souza, Programa Interinstitucional de Pós-Graduação em Ciências Fisiológicas UFSCAR-UNESP (Araraquara), São Carlos, SP, Brasil; Lab. Neuropsicofarmacologia, FCFAr-UNESP, Araraquara, SP, Brasil; Instituto de Neurociências \& Comportamento - INeC, USP, Ribeirão Preto, SP, Brasil. Tarciso Tadeu Miguel and Vanessa Cristiane Santana Amaral, Programa Interinstitucional de Pós-Graduação em Ciências Fisiológicas UFSCAR-UNESP Araraquara, São Carlos, SP, Brasil; Lab. Neuropsicofarmacologia, FCFAr-UNESP, Araraquara, SP, Brasil. Karina Santos Gomes, Lab. Neuropsicofarmacologia, FCFAr- like fight and flight responses (for review, see Graeff, 2004), the PAG modulates less vigorous defensive responses related to anxiety, such as threat avoidance and risk assessment (Bertoglio \& Zangrossi, 2006; Carvalho-Netto, Litvin, Nunes-de-Souza, Blanchard, \& Blanchard, 2007; McNaughton \& Corr, 2004; Mendes-Gomes \& Nunes-deSouza, 2005, 2009; Teixeira \& Carobrez, 1999;).

Chemical stimulation of the PAG can be performed by local glutamate NMDA ( $N$-methyl-D-aspartate) receptor activation. When injected into the dPAG, NMDA

UNESP, Araraquara, SP, Brasil; Instituto de Neurociências \& Comportamento - INeC, USP, Ribeirão Preto, SP, Brasil. Juliana Sayuri Fugimoto, Lab. Neuropsicofarmacologia, FCFArUNESP, Araraquara, SP, Brasil. Joyce Mendes-Gomes, Lab. Neuropsicofarmacologia, FCFAr-UNESP, Araraquara, SP, Brasil. Eduardo Ferreira de Carvalho-Netto, Genome Research Institute, University of Cincinnati, Cincinnati, OH, USA. Correspondence regarding this article should be directed to: Ricardo Luiz Nunes-deSouza. Phone: +55-16-33016983. Fax: +55-16-33016980. E-mail address: souzarn@fcfar.unesp.br 
receptor agonists elicit fight and flight reactions in rats (e.g., Bandler, 1988; Bittencourt, Carobrez, Zamprogno, Tufik, \& Schenberg, 2004) and mice (e.g., Beckett, Lawrence, Marsden, \& Marshall, 1992), whereas local microinjection of 2-amino-7-phosphonoheptanoic acid (AP-7), a competitive NMDA receptor antagonist, produces antiaversive-like effects in the elevated plus maze (EPM; Guimarães, Carobrez, De Aguiar, \& Graeff, 1991), a widely used animal model of anxiety.

Glutamate is a ubiquitous excitatory amino acid in the central nervous system. In addition to activating ionotropic NMDA receptors, glutamate is also able to activate two other ion channel-coupled receptors, the $\alpha$-amino-3hydroxy-5-methyl-4-isoxazole propionic acid (AMPA) receptor and kainate receptor (Heresco-Levy, 2003; Huntley, Vickers, \& Morrison, 1994; Ozawa, Kamiya, \& Tsuzuki, 1998; Seeburg, 1993), and a G-protein-coupled receptor (metabotropic receptor). These receptors are largely expressed in the PAG (Albin \& Gilman, 1990; Onstott, Mayer, \& Beitz, 1993; Schubert, Shaikh, \& Siegel, 1996). Glutamate NMDA receptor activation leads to cellular calcium influx, which triggers a cascade of intracellular events, including activation of nitric oxide synthase (NOS), an enzyme that produces nitric oxide (NO) by converting L-arginine to L-citroline, with nicotinamide adenine dinucleotide phosphate (NADPH) and $\mathrm{Ca}^{2+}$ as co-factors (Garthwaite, Garthwaite, Palmer, \& Moncada, 1989; Heresco-Levy, 2003; Mayer et al., 1991). NOS has at least three isoforms. Inducible NOS (iNOS) is involved in immunological reactions and activated by factors released during pathological events, such as cytokines that can induce a substantial release of NO. Two other NOS isoforms are constitutive forms that are present in vase endothelia (endothelial NOS [eNOS]) and neurons (neuronal NOS [nNOS]) (Guix, Uribesalgo, Coma, \& Muñhoz, 2005; Lamas, Marsden, Li, Tempst, \& Michel, 1992; Mungrue, Bredt, Stewart, \& Husain, 2003; Prast \& Philippu, 2001).

Similar to the proaversive effects produced by glutamate NMDA receptor agonists, injection of NO donors into the dorsolateral column of the PAG (dlPAG) produces fight and flight reactions in rats (De Oliveira, Del-Bel, \& Guimarães, 2001). In contrast, administration of NOS inhibitors, guanylate cyclase inhibitors, and a NO scavenger in this same region induces anxiolytic-like effects in the EPM (De Oliveira \& Guimarães, 1999; Guimarães, Beijamini, Moreira, Aguiar, \& de Lucca, 2005; Guimarães, De Aguiar, Del Bel, \& Ballejo, 1994).

This paper attempts to show that the roles played by glutamate NMDA receptors and the NO complex within the dPAG in defensive behavior in mice appear to depend on the magnitude or nature of the aversive stimuli. Whereas chemical stimulation of the dPAG elicits defensive reactions that are blocked by local infusion of a nNOS inhibitor, the behavioral defensive responses induced by a more naturalistic situation (e.g., exposure to the EPM) are sensitive to NOS inhibition only in animals pretreated with an NMDA receptor agonist in the same midbrain structure. However, when exposed to a more aversive situation (e.g., confrontation by a predator), inhibition of nNOS within the $\mathrm{APAG}$ attenuates defensive-like behaviors in mice.

\section{Defensive-like responses induced by chemical stimulation of the IPAG with NMDA infusion in mice: effects of nNOS inhibition}

As widely demonstrated in many laboratories (e.g., Bandler \& Carrive, 1988; Bittencourt et al., 2004; Blanchard \& Blanchard, 1988; CarvalhoNetto, Markham, Blanchard, Nunes-de-Souza, \& Blanchard, 2006), chemical stimulation of the dPAG (e.g., with NMDA infusion) induces a set of behavioral responses, such as jumping, running, and freezing, that last approximately 5 minutes. Immediately after (and sometimes during) intra-dPAG NMDA infusion, animals exhibit a sequence of apparently disoriented jumps intercalated with running. These explosive motor behaviors, especially jumping, last approximately 6090 seconds and are followed by running intercalated with periods of freezing for 60-120 seconds. These defensive-like behaviors are followed by a sequence of non-aversively motivated behaviors (e.g., walking and rearing). Figure 1 illustrates the effects of intra-dPAG injection of NMDA (.04 nmol) on jumping and rearing frequency and on running and freezing time (in seconds) over 5 minutes in mice pretreated with saline or .2-.4 nmol $\mathrm{N}^{\omega}$-propyl-L-arginine (NPLA, a highly selective and potent inhibitor of $\mathrm{nNOS} ; K_{\mathrm{i}}=57 \mathrm{nM}$ ) that displays 3158-fold and 149-fold selectivity for iNOS and eNOS, respectively (Zhang, Fast, Marletta, Martasek, \& Silverman, 1997), in the same midbrain site. Intra-dPAG infusions of NPLA $(.4 \mathrm{nmol})$ changed the defensive behaviors induced by intra-dPAG injections of NMDA. The excitatory amino acid induced a sudden sequence of jumping and running behaviors that were followed by a period of freezing. These results corroborate many previous studies(Bandler, 1988; Bandler \& Carrive, 1988; Beckett et al., 1992; De Oliveira et al., 2001; Molchanov \& Guimaraes, 1999), which demonstrated that intraPAG injections of glutamate receptor agonists produce defensive reactions in rodents. NPLA antagonized these NMDA-induced behavioral effects, suggesting that NO release within the PAG plays a role in defensive behavior. Intra-dPAG infusion of NMDA did not alter rearing frequency, but higher-dose NPLA increased this vertical exploratory behavior, an effect that was independent of the treatment combination (i.e. saline or NMDA). The increase in rearing frequency suggests that this nNOS inhibitor (.2 and $.4 \mathrm{nmol})$ does not provoke motor disruption, an effect previously reported with 
systemic injections of other NOS inhibitors (Del Bel, da Silva, \& Guimaraes, 1998; Del Bel, Souza, Guimaraes, da Silva, \& Nucci-da-Silva, 2002; Del Bel, da Silva, Guimaraes, \& Bermudez-Echeverry, 2004). Intra-dPAG NPLA injections appear to selectively reduce NMDAinduced behavioral responses (e.g., jumping, running, freezing) in mice. Altogether, these results suggest that NO, synthesized after glutamate NMDA receptor activation within the dPAG, may modulate defensive behaviors in this midbrain structure.

However, intra-dPAG NPLA fails to alter defensive behavior when mice are exposed to a more naturalistic situation (e.g., the EPM). The results shown below suggest that the role played by $\mathrm{NO}$ in emotional responsiveness appears to be dependent on glutamate NMDA receptor activation, at least within the mouse dPAG, and the type of aversive stimulus exposure.

Inhibition of nNOS within the dPAG fails to alter anxiety-like behavior in the mouse EPM

Figure 2 shows that inhibition of NO synthesis within the mouse $\mathrm{dPAG}$ neither increased nor decreased anxiety-like behavior in the EPM. Intra-dPAG infusion of 4 nmol NPLA completely blocked vigorous defensive-like behaviors (e.g., jumping and running) induced by NMDA infusion (.04 nmol) into the same site (Figure 1), and intra-dPAG NPLA infusions of this nNOS inhibitor at doses of .2, .4, and $.8 \mathrm{nmol}$ failed to attenuate anxiety-like behavior in the EPM (Figure 2). The failure of intra-dPAG NPLA to affect anxiety-like behavior suggests that the aversive experience in the EPM is not sufficient to induce an anxiogenic amount of NO synthesis within the mouse dPAG, suggesting that intra-dPAG NO likely does not play a role in anxietylike behavior elicited during EPM exposure in mice.

\section{Inhibition of nNOS within the dPAG attenuates anxiety-like behavior induced by intra-dPAG NMDA infusion in the mouse EPM}

Although intra-dPAG NPLA failed to alter indices of anxiety in the mouse EPM, NO synthesis appears to be important for the anxiogenic-like effects induced by local infusion of NMDA. We found that intra-dPAG injection of NMDA at a dose that did not produce any vigorous defensive-like behavior $(.02 \mathrm{nmol} / .1 \mu \mathrm{l})$ led mice to explore the open arms of the EPM less
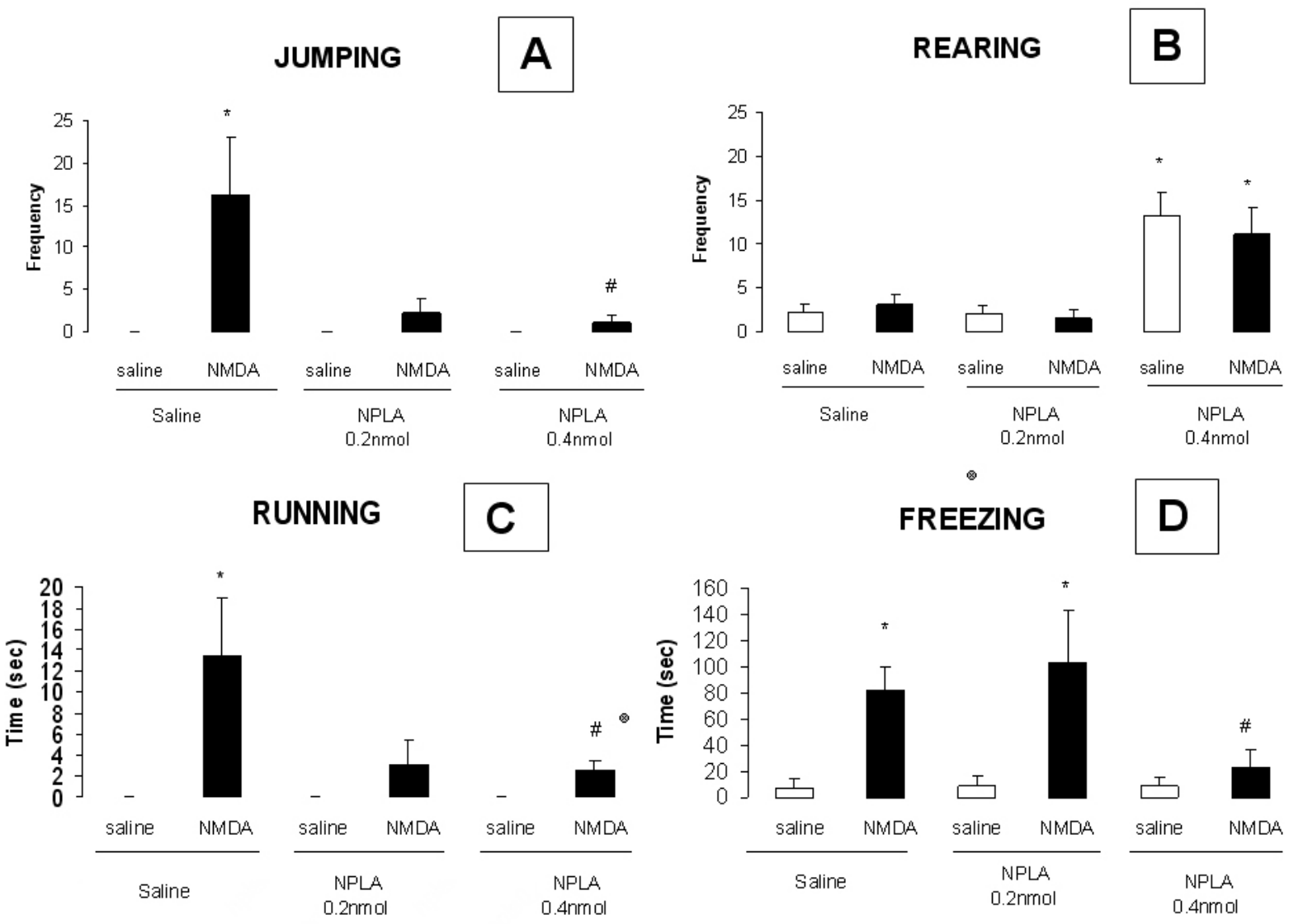

Figure 1. Effects of intra-dPAG injection of NMDA (0.04 nmol) on (A) jumping frequency, (B) rearing frequency, (C) running time (s), and (D) freezing time (s) over $5 \mathrm{~min}$ in mice pretreated with saline or NPLA (0.2-0.4 nmol) into the same midbrain site $\left(n=9-14\right.$; see text for details). ${ }^{*} p<.05$, compared with Saline+Saline; ${ }^{*} p<.05$, compared with Saline+NMDA (adapted from Miguel \& Nunes-de-Souza, 2006). 


\section{Anxiety Indices}

Entries $\square$ Time

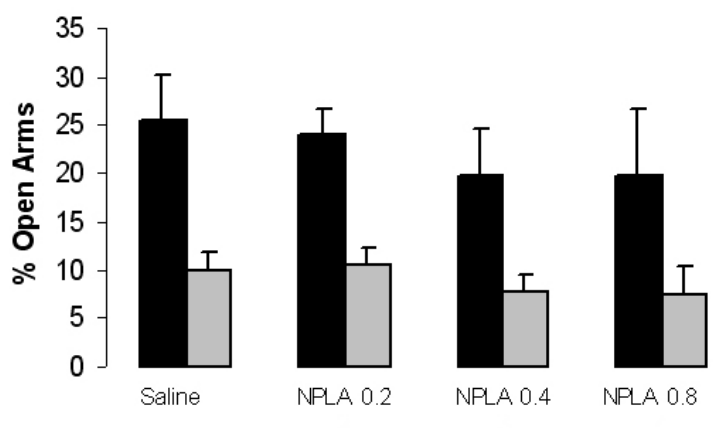

Treatment into the PAG

Figure 2. Effects of NPLA microinjection $(0, .2, .4$, and .8 nmol/0.1 $\mu \mathrm{l} ; n=9-15)$ into the dPAG on the percentage of open arm entries and percentage of open arm time in the EPM. Data are expressed as mean \pm SEM (reproduced from Miguel \& Nunes-de-Souza, 2008).

(Figure 3). This anxiogenic-like effect of NMDA was characterized by a selective reduction in the percentage of open arm entries and percentage of open arm time, the two main measures used as indices of anxiety in the EPM (e.g., File, 1992; Rodgers \& Johnson, 1995). These results corroborate previous findings that demonstrated an anxiogenic-like effect induced by glutamate NMDA receptor activation within the midbrain PAG in rodents (e.g., Bandler, 1988; Bittencourt et al., 2004).

Interestingly, when injected into the dPAG, NPLA completely blocked the enhancement of anxiety-like behavior induced by intra-PAG NMDA. As shown in Figure 4, intra-dPAG NPLA reversed the anxiogeniclike effects produced by local infusion of NMDA. Importantly, animals that received intra-dPAG injection of NPLA(NPLA+ saline) did not exhibit any significantly different behavior in the mouse EPM compared with

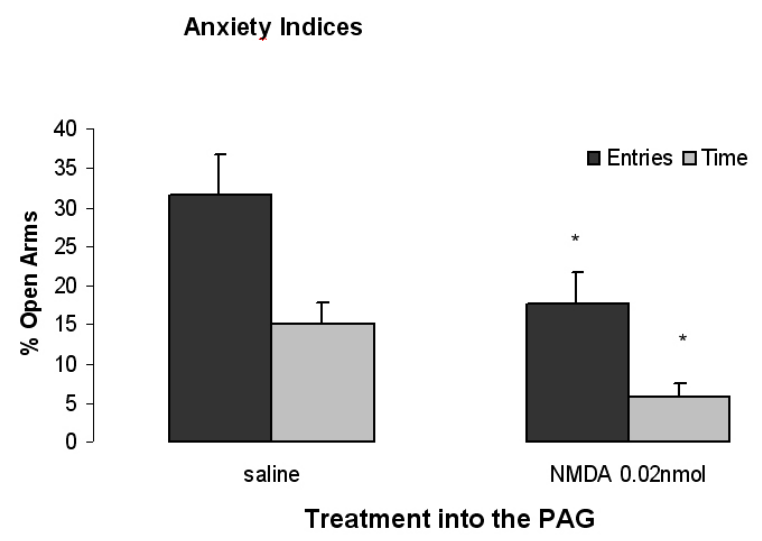

Figure 3. Effects of NMDA microinjection ( 0 and $.02 \mathrm{nmol} / .1 \mu \mathrm{l}$; $n=15-16)$ into the dPAG on the percentage of open arm entries and percentage of open arm time in the EPM. Data are expressed as mean \pm SEM. ${ }^{*} p<.05$, compared with control group (saline) (reproduced from Miguel \& Nunes-de-Souza, 2008). the control group (saline + saline). NMDA-injected animals (NMDA + saline), in turn, confirmed the results shown in Figure 3, showing an anxiogenic-like profile of this NMDA receptor agonist. These results indicate that glutamate NMDA receptor activation within the mouse PAG induces NO synthesis, which in turn leads to enhanced anxiety-like behavior in the EPM.

The mechanisms involved in the apparently contrasting effects of intra-dPAG NPLA on anxiety-like behavior (i.e., blockade of the anxiogenic-like effects of NMDA but inability to attenuate anxiety-like behavior when injected alone) are not clear. In fact, the existing data suggest that glutamatergic activation appears to be necessary to observe the effects of NO. However, this does not exclude a possible intrinsic anxiogenic-like effect of glutamate release during the exposure of mice to the EPM. Measuring glutamate release or NMDA receptor activation within the dPAG during the exposure of mice to the EPM would be interesting. In this context, we recently found that glutamate NMDA receptor blockade by intra-dPAG infusion of the NMDA receptor antagonist AP-7 attenuated anxiety-like behavior in mice exposed to the EPM (Figure 5). Intra-dPAG injection of AP-7 (.2 nmol/.1 $\mu \mathrm{l})$ increased open arm exploration without affecting closed arm entries (results not shown), suggesting a selective effect of this NMDA receptor antagonist on anxiety-like behavior. This anxiolytic-like profile produced by NMDA receptor blockade within the PAG was previously demonstrated in rats exposed to the EPM(Guimarães et al, 1991; Molchanov \& Guimarães, 2002).

The mechanisms underlying these apparently contrasting effects of intra-dPAG AP-7 and NPLA on anxiety-like behavior remain unclear. The results showing that intra-dPAG injection of AP-7 and NPLA

\section{Anxiety Indices}

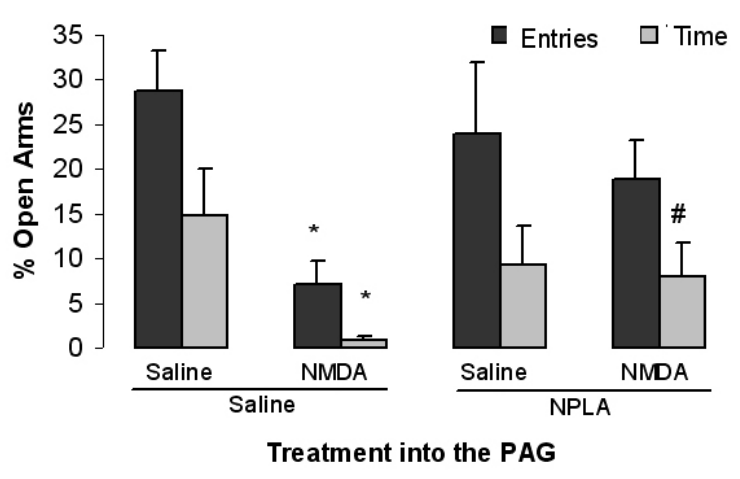

Figure 4. Effects of combined microinfusions of NPLA ( 0 and $.4 \mathrm{nmol} / .1 \mu \mathrm{l})$ and NMDA $(0$ and $.02 \mathrm{nmol} / .1 \mu \mathrm{l})$ into the $\mathrm{dPAG}$ on the percentage of open arm entries and percentage of open arm time in the EPM. Data are expressed as mean $\pm \operatorname{SEM}(n=$ $7-8) .{ }^{*} p<.05$, compared with control group (saline + saline); ${ }^{\#} p<.05$, compared with saline + NMDA group (adapted from Miguel \& Nunes-de-Souza, 2008). 


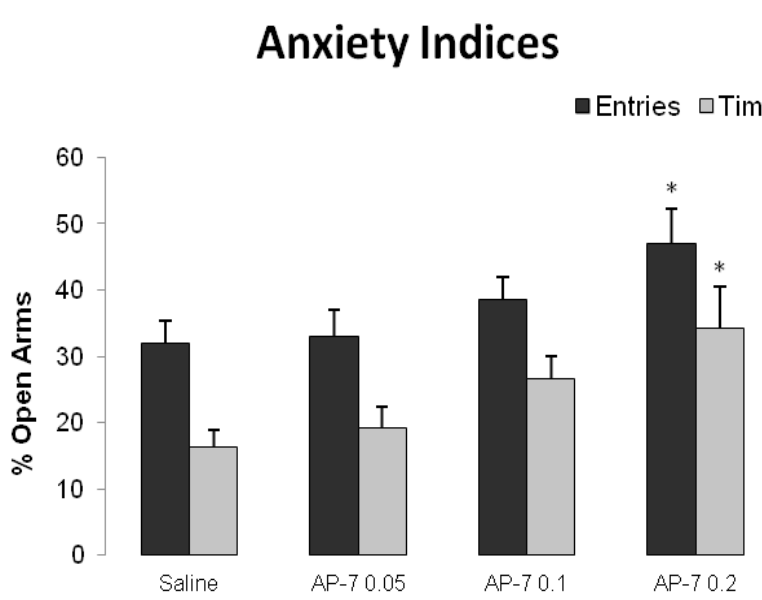

Treatment into the PAG $(\mathrm{nmol} / 0.1 \mu \mathrm{l})$

Figure 5. Effects of AP-7 microinjection $(0, .05, .1$, and .2 $\mathrm{nmol} / .1 \mu \mathrm{l} ; n=8-15)$ into the dPAG on the percentage of open arm entries and percentage of open arm time in the EPM. Data are expressed as mean \pm SEM. ${ }^{*} p<.05$, compared with control group (saline).

attenuated and did not alter, respectively, anxietylike behavior when injected alone suggest that the anxiogenic-like effect of glutamate NMDA receptor activation may not be completely dependent on NO synthesis. The anxiogenic-like effect of NO appears to depend on NMDA receptor "hyperactivation" within the mouse $\mathrm{dPAG}$, whereas glutamate NMDA receptor activation appears to play a tonic role in anxiety-like behavior. If so, then NMDA receptor activation would lead to neuronal excitation without affecting NO release. $\mathrm{Ca}^{2+}$ influx via NMDA receptor activation has been demonstrated to trigger subsequent and persistent changes in the expression of AMPA receptors, and these receptors are responsible for a substantial portion of basal excitatory postsynaptic potential (e.g., MacDonald, Jackson, \& Beazely, 2006).

Considering that intra-dPAG nNOS inhibition attenuated anxiety-like behavior only in animals pretreated with an NMDA receptor agonist, dPAG nitrergic modulation of defensive behavior may depend on the magnitude of the aversive stimulus to which mice are subjected. To test this hypothesis, we investigated the effects of intra-dPAG infusion of NPLA on defensive behavior in mice confronted by a predator (rat).

\section{Role of glutamate NMDA receptors and nitric oxide within the periaqueductal gray on defensive behaviors in mice confronted by a predator}

The rat exposure test (RET, Figure 6) is an animal model of anxiety based on the predator-prey (rat-mouse) interaction. The RET was developed and validated to facilitate the measurement of avoidance and risk assessment behaviors in mice (Yang et al., 2004). Testing procedures are conducted in a clear polycarbonate cage (exposure chamber) covered with a black polycarbonate lid. The exposure chamber is divided into two equally sized compartments by a wire mesh screen (surface and predator compartment). The home cage is a box made of black Plexiglas on three sides and clear Plexiglas on the fourth side to facilitate videotaping. The home chamber is connected to the exposure cage by a clear Plexiglas tube tunnel. Rats have been shown to be predators of mice both in nature and in the laboratory (Calvo-

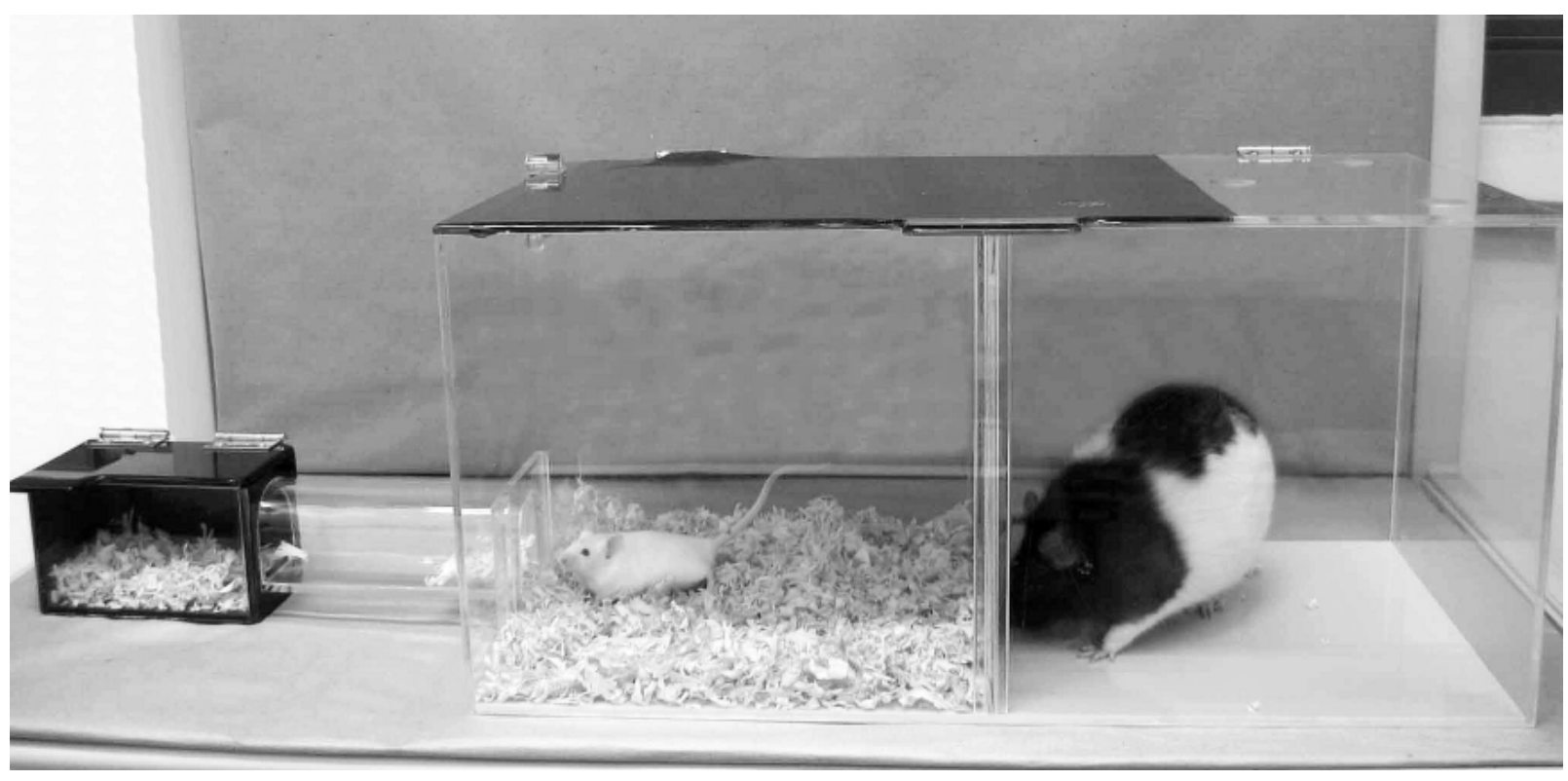

Figure 6. Photograph of rat exposure test apparatus. The predator (rat) is placed in the right half of the exposure cage, which is divided into two equally sized compartments by a wire mesh screen (surface and predator compartments) (reproduced from Amaral et al., 2010). 
Torrent, Brain, \& Martinez, 1999; O’Boyle 1974, 1975). When confronted by rats, both wild and laboratory mice show clear innate defensive behaviors (Blanchard et al., 1998). Recent studies have attempted to identify possible neurotransmitter systems and hormonal changes (e.g., plasma corticosterone) involved in the modulation of defensive responses in mice exposed to the RET (Amaral, Gomes, \& Nunes-de-Souza, 2010; CarvalhoNetto et al., 2007; Litvin, Pentowski, Blanchard, \& Blanchard, 2007; Martinez, Carvalho-Netto, Amaral, Nunes-de-Souza, \& Canteras, 2008).

In this context, we recently found that NPLA infusion into the $\mathrm{DPAG}$ attenuates the avoidance of the predator in the RET (Carvalho-Netto, Gomes, Amaral, \& Nunes-deSouza, 2009). Figure 7 shows the dose-response curve for NPLA treatment. The highest dose $(.4 \mathrm{nmol})$ increased the time in the surface compartment and in contact with the wire screen barrier between the mouse and predator. Additionally, intra-dPAG NPLA (.4 nmol) markedly reduced the duration of freezing behavior and risk assessment behavior, indicating that NLPA significantly reduced the spatiotemporal (avoidance) and ethological (freezing and risk assessment) measures of the RET, supporting the hypothesis of a potential role for the nitric oxide system in the dPAG in the regulation of anxiety-like behavior. Moreover, intra-dPAG NPLA also reversed the proaversive-like effect of NMDA injected into the same structure, suggesting a modulatory role for $\mathrm{NO}$ in defensive behavior induced by glutamate NMDA receptor activation within the dPAG (Carvalho-Netto et al., 2009).
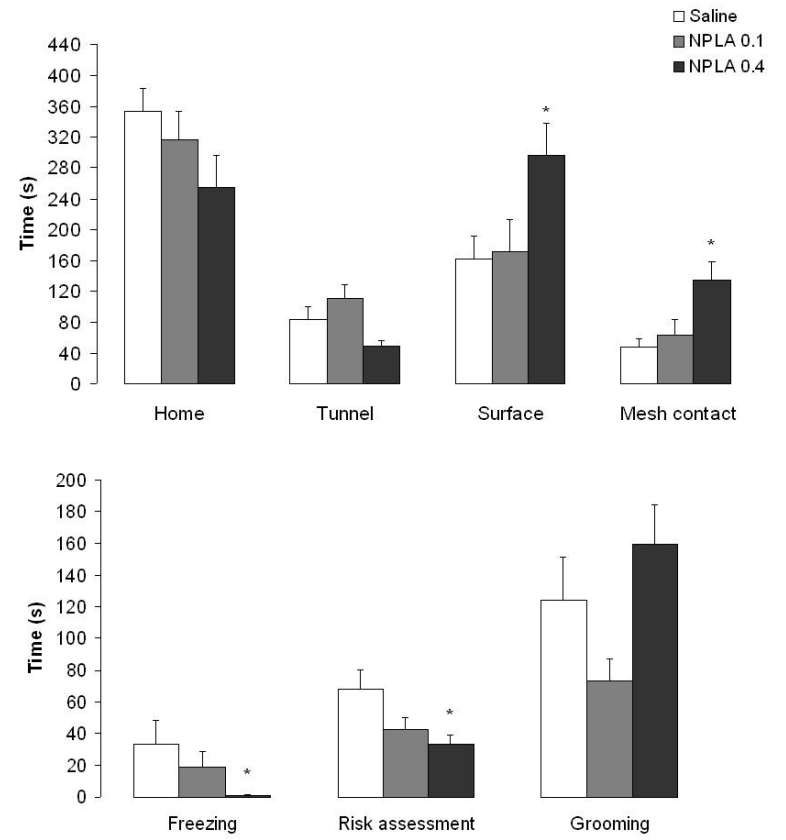

Figure 7. Effects of NPLA microinjection (.1 and $.4 \mathrm{nmol} / .1 \mu \mathrm{l}$; $n=9-15$ ) into the dPAG on the behaviors of mice in the RET. Each bar represents the mean \pm SEM. ${ }^{*} p<.05$, compared with control group (reproduced from Carvalho-Netto et al., 2009).

\section{Final considerations}

Based on previous studies (for review, see De Oliveira et al., 2001; Guimarães et al. 2005) and the present discussion, the effects of NPLA may represent an inhibition of NO production mediated by endogenous glutamatergic activation via NMDA receptors. Indeed, NMDA receptor activation has been established as the main stimulus for $\mathrm{NO}$ production in the central nervous system (for review, see Esplugues, 2002), and reciprocal regulatory mechanisms between these two neuronal pathways (glutamatergic and nitrergic) are likely to occur in the dPAG (Lin, Kang, Wan, Huang, \& Tseng, 2000). An elegant study reported by Beijamini and Guimarães (2006) showed that exposure to a cat activated NOSexpressing neurons in the rat $\mathrm{dPAG}$, an effect that was attenuated by prior intracerebroventricular microinjection of AP-7, a competitive NMDA receptor antagonist.

However, the failure of intra-dPAG NPLA to affect anxiety-like behavior in the EPM suggests that nitrergic neurotransmission located within this midbrain structure appears to not be recruited during the exposure of mice to this widely used animal model of anxiety. The scope of the present review was not to extensively compare the roles of glutamate NMDA receptors and NO in the dPAG on defensive behaviors in rats and mice. The existing literature suggests that the defensive response evaluated in the mouse EPM does not depend on NO synthesis within this limbic midbrain structure.

Previous studies have shown that mice exhibit a different behavioral defensive profile compared with rats (Blanchard et al., 1997; Blanchard, Griebel, \& Blanchard, 2001; Carvalho-Netto \& Nunes-de-Souza, 2004; Gomes et al., 2009; Jardim, Nogueira, Graeff, \& Nunes-de-Souza, 1999), suggesting species-specific neurobiological mechanisms. The inability of intradPAG NPLA to affect anxiety-like behavior in the mouse EPM contrasts with previous findings reported with the rat EPM. For example, Guimarães et al. (1994) showed that administration of $\mathrm{N}^{\mathrm{G}}$-nitro-L-arginine

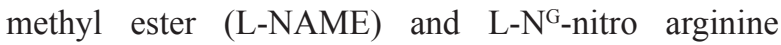
(L-NOARG) into the dPAG produced anxiolytic-like effects in the rat EPM. Altogether, these results suggest that the different effects of $\mathrm{NO}$ formation in the dPAG in rats and mice reflect a higher aversive state generated by the EPM in rats compared with mice. Importantly, however, L-NAME and L-NOARG are not selective nNOS inhibitors because they also inhibit eNOS (Pfeiffer, Leopold, Schmidt, Brunner, \& Mayer, 1996). Considering the evidence indicating the presence of eNOS within the PAG (Iwase et al., 2001; Paakkari \& Lindsberg, 1995), mechanisms other than, or in addition to, those involving nNOS in the rodent PAG may play a role in the modulation of anxiety-like behavior. Supporting this hypothesis are findings showing that eNOS also contributes to long-term potentiation (LTP) 
in the hippocampus (Hopper \& Garthwaite, 2006). These authors emphasized the importance of an integrated action of both isoenzymes (nNOS and eNOS) in LTP. Synaptic plasticity and neurochemical and behavioral evidence demonstrate the relevance of eNOS in other biological processes previously believed to be exclusive of nNOS action (Demas et al., 1999; Doreulee et al., 2003; Frisch et al., 2000; Haul, Godecke, Schrader, Haas, \& Luhmann, 1999; Kano, Shimizu-Sasamata, Huang, Moskowitz, \& Lo, 1998). Altogether, these findings suggest that the role of NO in anxiety-like behavior in the EPM appears to depend on the combined action of both enzyme isoforms within the mouse PAG. Further studies are required to confirm the anxiolyticlike profile of eNOS in this midbrain structure.

\section{Acknowledgements}

The authors thank FAPESP, CNPq, and PADC/FCF Unesp for financial support.

\section{References}

Albin, R.L., \& Gilman, S. (1990). Autoradiographic localization of inhibitory and excitatory amino acid neurotransmitter receptors in human normal and olivopontocerebellar atrophy cerebellar cortex. Brain Research, 522, 37-45.

Amaral, V.C.S., Gomes, K.S., \& Nunes-de-Souza, R.L. (2010) Increased corticosterone levels in mice subjected to the rat exposure test. Hormones and Behavior, 57, 128-133.

Bandler, R. (1988). Brain mechanisms of aggression as revealed by electrical and chemical stimulation: suggestion of a central role for the midbrain periaquedutal gray region. In: A.N. Epstein \& A.R. Horrison (Eds.), Progress in psychobiology and physiological psychology, vol. 13 (pp. 67-154). San Diego: Academic Press.

Bandler, R., \& Carrive, P. (1988). Integrated defense reaction elicited by excitatory amino acid microinjection in the midbrain periaquedutal gray region of the unrestrained cat. Brain Research, 439, 95-106.

Beckett, S.R., Lawrence, A.J., Marsden, C.A., \& Marshall, P.W. (1992). Attenuation of chemically induced defence response by 5-HT receptor agonists administered into the periaqueductal gray. Psychopharmacology, 108, 110-114.

Beijamini, V., \& Guimarães, F.S. (2006). c-Fos expression increase in NADPH-diaphorase positive neurons after exposure to a live cat. Behavioural Brain Research, 170, 52-61.

Bertoglio, L.J., \& Zangrossi, H., Jr. (2006). Involvement of dorsolateral periaqueductal gray $N$-methyl-D-aspartic acid glutamate receptors in the regulation of risk assessment and inhibitory avoidance behaviors in the rat elevated T-maze. Behavioural Pharmacology, 17, 589-596 [erratum: 17, 737].

Bittencourt, A.S., Carobrez, A.P., Zamprogno, L.P., Tufik, S., \& Schenberg, L.C., (2005). Organization of single components of defensive behaviors within distinct columns of periaqueductal gray matter of the rat: role of $N$-methyl-D-aspartic acid glutamate receptors. Neuroscience, $125,71-89$

Blanchard, D.C., \& Blanchard, R.J. (1988). Ethoexperimental approaches to the biology of emotion. Annual Review of Psychology, 39, 43-68.

Blanchard, D.C., Griebel, G., \& Blanchard, R.J. (2001). Mouse defense behaviors: pharmacological and behavioral assays for anxiety and panic. Neuroscience and Biobehavioral Reviews, 25, 205-218.

Blanchard, R.J., Griebel, G., Henrie, J.A., \& Blanchard, D.C. (1997). Differentiation of anxiolytic and panicolytic drugs by effects on rat and mouse defense test batteries. Neuroscience and Biobehavioral Reviews, 21, 783-789.

Blanchard, R.J., Hebert, M.A., Ferrari, P.F., Palanza, P., Figueira, R., Blanchard, D.C., \& Parmigiani, S. (1998). Defensive behaviors in wild and laboratory (Swiss) mice: the mouse defense test battery.
Physiology and Behavior, 65, 201-209.

Calvo-Torrent, A., Brain, P.F., \& Martinez, M. (1999). Effect of predatory stress on sucrose intake and behavior on the plus-maze in male mice. Physiology and Behavior, 67, 189-196.

Carvalho-Netto, E.F., Gomes, K.S., Amaral, V.C.S., \& Nunes-deSouza, R.L. (2009). Role of glutamate NMDA receptors and nitric oxide located within the periaqueductal gray on defensive behaviors in mice confronted by predator. Psychopharmacology, 204, 617-625.

Carvalho-Netto, E.F., Litvin, Y., Nunes-de-Souza, R.L., Blanchard, D.C., \& Blanchard, R.J. (2007). Effects of intra-PAG infusion of ovine CRF on defensive behaviors in Swiss-Webster mice. Behavioural Brain Research, 176, 222-229.

Carvalho-Netto, E.F., Markham, C., Blanchard, D.C., Nunes-de-Souza, R.L., \& Blanchard, R.J. (2006). Physical environment modulates the behavioral responses induced by chemical stimulation of dorsal periaqueductal gray in mice. Pharmacology Biochemistry and Behavior, 85, 140-147.

Carvalho-Netto, E.F., \& Nunes-de-Souza, R.L. (2004). Use of elevated T-maze to study anxiety in mice. Behavioural Brain Research, 148, 119-132.

De Oliveira, R.W., \& Guimarães, F.S. (1999). Anxiolytic effect of methylene blue microinjected into the dorsal periaqueductal gray matter. Brazilian Journal of Medical and Biological Research, 32, 1529-1532.

De Oliveira, R.M., Del Bel, E.A., \& Guimaraes, F.S. (2001). Effects of excitatory amino acids and nitric oxide on flight behavior elicited from the dorsolateral periaquedutal gray. Neuroscience and Biobehavioral Reviews, 25, 679-685.

Del Bel, E.A., da Silva, C.A., \& Guimaraes, F.S. (1998). Catalepsy induced by nitric oxide synthase inhibitors. General Pharmacology, 30, 245-248.

Del Bel E.A., da Silva, C.A., Guimaraes F.S., \& Bermudez-Echeverry, M. (2004). Catalepsy induced by intra-striatal administration of nitric oxide synthase inhibitors in rats. European Journal of Pharmacology, 485, 175-181.

Del Bel, E.A., Souza, A.S., Guimaraes, F.S., da Silva, C.A., \& Nuccida-Silva, L.P. (2002). Motor effects of acute and chronic inhibition of nitric oxide synthesis in mice. Psychopharmacology, 161, 32-37.

Demas, G.E., Kriegsfeld, L.J., Blackshaw, S., Huang, P., Gammie, S.C., Nelson, R.J., \& Snyder, S.H. (1999). Elimination of aggressive behavior in male mice lacking endothelial nitric oxide synthase. Journal of Neuroscience, 19, RC30.

Doreulee, N., Sergeeva, O.A., Yanovsky, Y., Chepkova, A.N., Selbach, O., Godecke, A., Schrader, J., \& Haas, H.L. (2003). Cortico-striatal synaptic plasticity in endothelial nitric oxide synthase deficient mice. Brain Research, 964, 159-163.

Esplugues, J. (2002). NO as a signaling molecule in the nervous system. British Journal of Pharmacology, 135, 1079-1095.

File, S.E. (1992). Behavioural detection of anxiolytic action. In: J.M. Elliott, D.J. Heal \& C.A. Marsden (Eds.), Experimental approaches to anxiety and depression (pp. 25-44). Chichester: Wiley.

Frisch, C., Dere, E., Silva, M.A., Godecke, A., Schrader, J., \& Huston, J.P. (2000). Superior water maze performance and increase in fearrelated behavior in the endothelial nitric oxide synthase-deficient mouse together with monoamine changes in cerebellum and ventral striatum. Journal of Neuroscience, 20, 6694-6700.

Garthwaite, J., Garthwaite, G., Palmer, R.M., \& Moncada, S. (1989). NMDA receptor activation induces nitric oxide synthesis from arginine in rat brain slices. European Journal of Pharmacology, $172,413-416$.

Gomes, K.S., Carvalho-Netto, E.F., Monte, K.C., Acco, B., Nogueira, P.J., \& Nunes-de-Souza, R.L. (2009). Contrasting effects of acute and chronic treatment with imipramine and fluoxetine on inhibitory avoidance and escape responses in mice exposed to the elevated T-maze. Brain Research Bulletin, 78, 323-327.

Graeff, F.G. (2004). Serotonin, the periaqueductal gray and panic. Neuroscience and Biobehavioral Reviews, 28, 239-259.

Guimarães, F.S., Beijamini, V., Moreira, F.A., Aguiar, D.C., \& de Lucca, A.C. (2005). Role of nitric oxide in brain regions related to defensive reactions. Neuroscience and Biobehavioral Reviews, $29,1313-1322$

Guimarães, F.S., Carobrez, A.P., De Aguiar, J.C., \& Graeff, F.G. (1991). Anxiolytic effect in the elevated plus-maze of NMDA receptor antagonist AP7 microinjected into the dorsal periaqueductal grey. Psychopharmacology, 103, 91-94. 
Guimarães, F.S., De Aguiar, J.C., Del Bel, E.A., \& Ballejo, G. (1994). Anxiolytic effect of nitric oxide synthase inhibitors microinjected into the dorsal central grey. Neuroreport, 5, 1929-1932.

Guix, F.X., Uribesalgo, I., Coma, M., \& Muñoz, F.J. (2005). The physiology and pathophysiology of nitric oxide in the brain. Progress in Neurobiology, 76, 126-152.

Haul, S., Godecke, A., Schrader, J., Haas, H.L., \& Luhmann, H.J. (1999). Impairment of neocortical long-term potentiation in mice deficient of endothelial nitric oxide synthase. Journal of Neurophysiology, 81, 494-497.

Heresco-Levy, U. (2003). Glutamatergic neurotransmission modulation and the mechanisms of antipsychotic atypicality. Progress in Neuropsychopharmacology and Biological Psychiatry, 27, 1113-1123.

Hopper, R.A., \& Garthwaite, J. (2006). Tonic and phasic nitric oxide signals in hippocampal long-term potentiation. Journal of Neuroscience, 26, 11513-11521.

Huntley, G.W., Vickers, J.C., \& Morrisson, J.H. (1994). Cellular and synaptic localization of NMDA and non-NMDA receptor subunits in neocortex: organizational features related to cortical circuitry, function and disease. Trends in Neurosciences, 17, 536-543.

Iwase, K., Miyanaka, K., Shimizu, A., Nagasaki, A., Gotoh, T., Mori, M., \& Takiguchi, M. (2000). Induction of endothelial nitric-oxide synthase in rat brain astrocytes by systemic lipopolysaccharide treatment. Journal of Biological Chemistry, 275, 11929-11933.

Jardim, M.C., Nogueira, R.L., Graeff, F.G., \& Nunes-de-Souza, R.L. (1999). Evaluation of the elevated T-maze as an animal model of anxiety in the mouse. Brain Research Bulletin, 48, 407-411.

Kano, T., Shimizu-Sasamata, M., Huang, P.L., Moskowitz, M.A., \& Lo, E.H. (1998). Effects of nitric oxide synthase gene knockout on neurotransmitter release in vivo. Neuroscience, 86, 695-699.

Lamas, S., Marsden, P.A., Li, G.K., Tempst, P., \& Michel, T. (1992). Endothelial nitric oxide synthase: molecular cloning and characterization of a distinct constitutive enzyme isoform. Proceedings of the National Academy of Sciences of the United States of America, 89, 6348-6352.

Lin, H.C., Kang, B.H., Wan, F.J., Huang, S.T., \& Tseng, C.J. (2000). Reciprocal regulation of nitric oxide and glutamate in the nucleus tractus solitarii of rats. European Journal of Pharmacology, 407, 83-89.

Litvin, Y., Pentowski, N.S., Blanchard, D.C., \& Blanchard, R.J. (2007). CRF type 1 receptors in the dorsal periaqueductal gray modulate anxiety-induced defensive behaviors. Hormones and Behavior, 52, 244-251.

MacDonald, J.F., Jackson, M.F., \& Beazely, M.A. (2006). Hippocampal long-term synaptic plasticity and signal amplification of NMDA receptors. Critical Reviews in Neurobiology, 18, 71-84.

Martinez, R.C., Carvalho-Netto, E.F., Amaral, V.C.S., Nunesde-Souza, R.L., \& Canteras, N.S. (2008). Investigation of the hypothalamic defensive system in the mouse. Behavioural Brain Research, 192, 185-190.

Mayer, B., John, M., Heinzel, B., Werner, E.R., Wachter, H., Schultz, G., \& Bohme, E. (1991). Brain nitric oxide synthase is a biopterinand flavin-containing multi-functional oxido-reductase. FEBS Letters, 288, 187-191.

McNaughton, N., \& Corr, P.J. (2004). A two-dimensional neuropsychology of defense: fear/anxiety and defensive distance. Neuroscience and Biobehavioral Reviews, 28, 285-305.

Mendes-Gomes, J., \& Nunes-de-Souza, R.L. (2005). Concurrent nociceptive stimulation impairs the anxiolytic effect of midazolam injected into the periaqueductal gray in mice. Brain Research, 1047, 97-104.

Mendes-Gomes, J., \& Nunes-de-Souza, R.L. (2009). Anxiolytic-like effects produced by bilateral lesion of the periaqueductal gray in mice: influence of concurrent nociceptive stimulation. Behavioural Brain Research, 203, 180-187.

Miguel, T.T., \& Nunes-de-Souza, R.L. (2006). Defensive-like behaviors and antinociception induced by NMDA injection into the periaqueductal gray of mice depend on nitric oxide synthesis. Brain Research, 1076, 42-48.

Miguel, T.T., \& Nunes-de-Souza, R.L. (2008). Anxiogenic-like effects induced by NMDA receptor activation are prevented by inhibition of neuronal nitric oxide synthase in the periaqueductal gray in mice. Brain Research, 1240, 39-46.

Molchanov, M.L., \& Guimaraes, F.S. (1999). Defense reaction induced by a metabotropic glutamate receptor agonist microinjected into the dorsal periaqueductal gray of rats. Brazilian Journal of Medical and Biological Research, 32, 1533-1537.

Molchanov, M.L., \& Guimaraes, F.S. (2002). Anxiolytic-like effects of AP7 injected into the dorsolateral or ventrolateral columns of the periaqueductal gray of rats. Psychopharmacology, 160, 30-38.

Mungrue, I.N., Bredt, D.S., Stewart, D.J., \& Husain, M. (2003). From molecules to mammals: what's NOS got to do with it? Acta Physiologica Scandinavica, 179, 123-135.

O'Boyle, M. (1974). Rats and mice together: the predatory nature of the rat's mouse-killing response. Psychological Bulletin, 81, 261-269.

O'Boyle, M. (1975). The rat as a predator. Psychological Bulletin, 82, 460-462.

Onstott, D., Mayer, B., \& Beitz, A.J. (1993). Nitric oxide synthase immunoreactive neurons anatomically define a longitudinal dorsolateral column within the midbrain periaqueductal gray of the rat: analysis using laser confocal microscopy. Brain Research, 610, 317-324.

Ozawa, S., Kamiya, H., \& Tsuzuki, K. (1998). Glutamate receptors in the mammalian central nervous system. Progress in Neurobiology, 54, 581-618.

Paakkari, I., \& Lindsberg, P. (1995). Nitric oxide in the central nervous system. Annals of Medicine, 27, 369-377.

Pfeiffer, S., Leopold, E., Schmidt, K., Brunner, F., \& Mayer, B. (1996). Inhibition of nitric oxide synthesis by $\mathrm{N}^{\mathrm{G}}$-nitro-L-argine methyl ester (L-NAME): requirement for bioactivation to the free acid, $\mathrm{N}^{\mathrm{G}}$-nitro-L-arginine. British Journal of Pharmacology, 118, 1433-1440.

Prast, H., \& Philippu, A. (2001). Nitric oxide as a modulator of neuronal function. Progress in Neurobioliogy, 64, 51-68.

Rodgers, R.J., \& Johnson, N.J.T. (1995). Factor analysis of spatiotemporal and ethological measures in the murine elevated plus-maze test of anxiety. Pharmacology Biochemistry and Behavior, 52, 297-303.

Schubert, K., Shaikh, M.B., \& Siegel, A. (1996). NMDA receptors in the midbrain periaqueductal gray mediate hypothalamically evoked hissing behavior in the cat. Brain Research, 726, 80-90.

Seeburg, P.H. (1993). The TiPS/TINS lecture: the molecular biology of mammalian glutamate receptor channels. Trends in Pharmacological Sciences, 14, 297-303.

Teixeira, K.V., \& Carobrez, A.P. (1999). Effects of glycine or (+/-)-3-amino-1-hydroxy-2-pyrrolidone microinjections along the rostrocaudal axis of the dorsal periaqueductal gray matter on rats' performance in the elevated plus-maze task. Behavioral Neuroscience, 113, 196-203.

Yang, M., Augustsson H., Markham, C.M., Hubbard DT., Webster D., Wall, P.M., Blanchard, R.J., \& Blanchard, D.C. (2004). The rat exposure test: a model of mouse defensive behaviors. Physiology and Behavior, 81, 465-473.

Zhang, H.Q., Fast, W., Marletta, M.A., Martasek, P., \& Silverman, R.B. (1997). Potent and selective inhibition of neuronal nitric oxide synthase by $\mathrm{N}^{\omega}$-propyl-L-arginine. Journal of Medicinal Chemistry, 40, 3869-3870. 